\title{
PENGARUH PEMBELAJARAN REMEDIAL TERHADAP HASIL BELAJAR MATEMATIKA TEKNIK
}

\author{
Ukti Lutvaidah $^{1}$, Bambang Perkasa Alam², Ryan Hidayat ${ }^{3}$ \\ ${ }^{1}$ Universitas Indraprasta PGRI, Program Studi Arsitektur \\ uktilutvaidah03@gmail.com \\ ${ }^{2}$ Universitas Indraprasta PGRI, Program Studi Arsitektur \\ perkasaalam.bambang@gmail.com \\ ${ }^{3}$ Universitas Indraprasta PGRI, Program Studi Arsitektur \\ ryansastra3@gmail.com
}

\begin{abstract}
The ability that every student has in understanding the material being taught varies a fast, moderate, slow, even difficult one. Students who are experiencing slow or difficult to understand the material will not be completed in the results of their studies. Students 'right to gain the same knowledge for each other is therefore the uncompleted students are given remedial instruction. This research aims to determine the difference in learning outcomes for students of the first semester of the architecture study Program of the University of Indraprasata PGRI taught using peer-to-peer tutoring methods in remedial teaching. And know the student's response to the implementation of remedial learning program that has been implemented. Types of experimental research with quantitative approaches and data collection techniques. Using documentation methods, test methods and interview methods. The results of the study showed Thitung $=0.195<$ This $=1.671$ which means there is a significant difference in the increase in learning outcomes among students taught using the peer tutor method with learners taught using the method of assigning assignments in remedial teaching. And the student's response to the implementation of remedial learning programs that have been implemented positively on average, recorded to understand the material being taught and found a solution to the difficulty in the learning process.
\end{abstract}

Keywords: Remedial Teaching, Peer Tutor methods, assignment methods, learning outcomes

\begin{abstract}
Abstrak. Kemampuan yang dimiliki setiap mahasiswa dalam memahami materi yang diajarkan berbeda-beda ada yang cepat, sedang, lambat, bahkan sulit. Mahasiswa yang mengalami lambat atau kesulitan dalam memahami materi akan tidak tuntas pada hasil belajarnya. Hak mahasiswa untuk mendapatkan pengetahuan yang sama satu sama lainnya oleh karena itu mahasiswa yang dinyatakan tidak tuntas diberikan pengajaran remedial. Penelitian ini bertujuan untuk mengetahui perbedaan peningkatan hasil belajar bagi mahasiswa semester I Program Studi Arsitektur Universitas Indraprasata PGRI yang diajarkan menggunakan metode tutor sebaya dengan metode pemberian tugas dalam pengajaran remedial. Serta mengetahui respon mahasiswa terhadap penerapan program pembelajaran remedial yang telah dilaksanakan. Jenis penelitian eksperimen dengan pendekatan kuantitatif dan teknik pengumpulan data .menggunakan metode dokumentasi, metode tes dan metode wawancara. Hasil penelitian menunjukan $\mathrm{t}_{\text {hitung }}=0,195<\mathrm{t}_{\text {tabel }}=$ 1,671 yang artinya adanya perbedaan yang signifikan peningkatan hasil belajar antara mahasiswa yang diajarkan menggunakan metode tutor sebaya dengan peserta didik yang diajarkan menggunakan metode pemberian tugas dalam pengajaran remedial. Dan respon mahasiswa terhadap penerapan program pembelajaran remedial yang telah dilaksanakan rata-rata positif, merekan menjadi paham tentang materi yang diajarkan dan menemukan solusi dalam mengetasi kesulitan dalam belajarnya.
\end{abstract}

Kata Kunci : Pengajaran Remedial, Metode Tutor Sebaya, Metode Pemberian Tugas, Hasil Belajar

\section{PENDAHULUAN}

Matematika adalah ilmu tentang angka atau bilangan, bangun, hubungan-hubungan konsep, dan logika dengan menggunakan bahasa lambang atau simbol dalam menyelesaikan masalah-masalah dalam kehidupan sehari-hari. Matematika juga merupakan pengetahuan yang didasarkan 
pada pola deduktif, hal ini sesuai dengan pendapat Jujun S. Suriasumantri (2009: 199) yaitu "matematika pada garis besarnya merupakan pengetahuan yang disusun secara konsisten berdasarkan logika deduktif". Logika deduktif adalah cara berfikir dengan menarik kesimpulan dari kategori umum menjadi khusus.

Menurut Tatan dan Teti (2011: 73), "Belajar selalu melibatkan perubahan dalam diri individu seperti kematangan berfikir, perilaku maupun kedewasaan dalam menentukan keputusan dan pilihan". Belajar akan menjadikan seseorang mengetahui banyak hal sehingga kemampuan-kemampuan yang dimiliki akan berubah dan berkembang menjadi lebih baik. Perubahan dan perkembangan kemampuan seseorang tersebut yang dinamakan hasil belajar. Perubahan dan perkembangan kemampuan itu pula yang membedakan hasil belajar antara manusia dengan makhluk lainnya, seperti hewan.

Setiap mahasiswa memiliki kepribadian yang unik, antara mahasiswa satu dengan mahasiswa yang lain mempunyai perbedaan yang beranekaragam. Baik dalam tingkat kecerdasan, daya ingat, kondisi fisik, maupun kemampuan dalam mengendalikan emosi. Padahal pada umumnya mahasiswa menerima layanan pendidikan yang sama, selain itu proses belajar mengajar masih bersifat klasikal, dimana guru lebih mendominasi proses pembelajaran dengan seringnya menggunakan metode ceramah. Sehingga sedikit tuntutan aktif dari siswa akibatnya, ada beberapa siswa yang prestasi belajarnya jauh di bawah Kriteria Ketuntasan Minimal (KKM) yang telah ditetapkan pada masing-masing mata kuliah.

Salah satu mata kuliah yang beberapa mahasiswanya masih kurang bisa memahami materi sehingga nilai ujiannya masih dibawah KKM adalah Matematika Teknik. Padahal matematika teknik merupakan mata kuliah yang wajib dimengerti oleh mahasiswa karena materi yang dipelajari akan diguanakan pada mata kuliah yang lainnya yang ada perhitungannya. Selain itu dengan belajar matematika teknik diharapkan mahasiswa menjadi lebih berpikir logis, teiti, ulet, dan bekerja keras.

Kondisi nilai hasil ujian tengan semester mata kuliah matematika teknik pada mahasiswa Semester I Program Studi Arsitektur Universitas Indraprasata PGRI yang rendah, memaksa dosen untuk mengambil tindakan yang tepat. Jika kesulitan belajar mahasiswa dibiarkan, maka tujuan pembelajaran tidak akan tercapai dengan baik. Dalam proses pembelajaran, akan selalu ada beberapa mahasiswa yang memerlukan bantuan baik dalam hal mencerna materi pelajaran maupun dalam mengatasi kesulitankesulitan belajar yang dialaminya. Sering ditemui beberapa mahasiswa Semester I Program Studi Arsitektur Universitas Indraprasata PGRI yang tidak mampu mencapai KKM yang telah ditentukan. Hasil belajar seorang mahasiswa kadang-kadang berada di bawah rata-rata bila dibandingkan dengan hasil belajar teman-teman sekelasnya. Mahasiswa-mahasiswa seperti inilah yang memperoleh pengajaran remedial.

Kegiatan remedial (perbaikan) dalam proses pembelajaran merupakan salah satu kegiatan pemberian bantuan yang berupa kegiatan perbaikan yang telah diprogram dan disusun secara sistematis. Dengan kata lain, pengajaran perbaikan (remedial teaching) ini berfungsi terapis untuk penyembuhan. Dalam hal ini, yang disembuhkan adalah beberapa hambatan atau gangguan kepribadian yang berkaitan dengan kesulitan belajar sehingga berakibat timbal balik dalam arti, perbaikan belajar juga perbaikan pribadi dan sebaliknya. Maksudnya, jika ternyata hasil yang dicapai tidak memuaskan, mahasiswa masih dipandang belum mencapai hasil belajar yang diharapkan, maka diperlukan suatu proses pengajaran yang dapat membantu tercapainya hasil belajar yang diharapkan.

Sejalan dengan pendapat Ahmadi (2013:152), beliau menyatakan bahwa "pengajaran remedial atau perbaikan adalah suatu bentuk pengajaran yang bersifat menyembuhkan atau membetulkan, atau dengan singkat pengajaran dengan singkat membuat menjadi baik". Dengan diadakan pengajaran remedial diharapkan selain 
mahasiswa memperoleh nilai diatas KKM, mahasiswa lebih paham dengan materi yang sebelumnya mereka tidak paham. Program pembelajaran remedial disesuaikan dengan karakteristik kesulitan belajar mahasiswa dan tingkat kemampuan mahasiswa. Seperti yang dikatakan oleh Sukardi (2008: 228) bahwa "pengajaran remidial tidak lain adalah termasuk kegiatan pengajaran yang tepat diterapkan, hanya ketika kesulitan belajar dasar siswa telah diketahui. Berdasarkan pendapat tersebut maka penting bagi pengajar untuk mendiagnosa kesulitan yang dialami oleh peserta didik sehingga dalam pemilihan metode pembelajaran yang akan ditearapkan akan tepat.

Metode yang digunakan dalam penelitian ini yaitu metode tutor sebaya dan metode pemberian tugas. Menurut Yulitta Radita Kusumasari (2007: 21) menyatakan bahwa tutor sebaya adalah pemanfaatan siswa yang mempunyai keistimewaan, pandai, dan kecakapan di dalam kelas untuk memberi penjelasan, bimbingan dan arahan kepada siswa yang kepandaiannya kurang atau lambat dalam menerima pelajaran yang usianya hampir sama sekelas dalam pengajaran remedial. Dengan diterapkan metode tutor sebaya diharapkan mahasiswa yang mengalami kesulitan dalam memahami materi dapat menanyakan pada temannya yang menjadi tutor tanpa harus ada rasa takut dan malu, lebih terbuka untuk mendapatkan solusi atas permasalahan yang dihadapi.

Mulyadi (2010: 77-78) menyatakan bahwa metode pemberian tugas adalah suatu metode yang diberikan guru dengan memberikan tugas-tugas tertentu kepada murid baik secara kelompok maupun secara individual, kemudian mereka diminta pertanggung jawaban atas tugas-tugas tersebut. Murid-murid yang mengalami kesulitan belajar dapat dibantu melalui kegiatan-kegiatan melaksanakan tugas-tugas tertentu, sehingga murid dapat bekerja dan mengatasi masalah yang dihadapi dengan ketrampilan dan kemampuan yang ada pada dirinya. Pemberian tugas harus memperhatikan jenis kesulitan yang dihadapi mahasiswa agar mereka mengevaluasi untuk mencari solusi yang lain dalam memecahkan permasalahan yang dihadapi.

Dalam proses pembelajaran, seorang pengajar sangat diharapkan untuk dapat menciptakan situasi pembelajaran yang efektif, efisien dan relevan. Agar hal ini dapat tercapai, maka seorang harus memiliki kompetensi yang beraneka ragam. Salah satu kompetensi yang dimaksud adalah bahwa seorang pengajar harus mempunyai kemampuan untuk melakukan diagnosis kesulitan belajar mahasiswa. Artinya, ia bukan saja harus dapat menganalisis bahan pelajaran yang disampaikannya, tetapi juga berbagai kesulitan yang mungkin dialami mahasiswa dalam menerima pelajaran yang disampaikan.

Berdasarkan latar belakang yang telah dipaparkan, penelitian ini bertujuan untuk mengetahui peningkatan hasil belajar matematika teknik pada mahasiswa Semester I Program Studi Arsitektur Universitas Indraprasata PGRI yang mengalami kesulitan belajar dengan diberikan pendekatan berupa kegiatan pembelajaran remedial. Serta untuk mengetahui respon mahasiswa terhadap penerapan program pembelajaran remedial yang telah dilaksanakan. Target penelitian ini untuk mengetahui kesulitan yang dialami mahasiswa dalam memahami materi yang diajarkan dan mencari solusinya dalam memecahkan permasalahan tersebut sehingga mahasiswa mendapatkan nilai diatas KKM setelah mendapatkan pengajaran remedial.

\section{METODOLOGI \\ Jenis Penelitian}

Jenis yang digunakan dalam penelitian ini adalah eksperimen dengan pendekatan yang digunakan dalam penelitian ini adalah pendekatan kuantitatif dimana pendekatan ini melakukan perhitungan yang diperoleh dari hasil tes uji pada sampel.

\section{Waktu dan Tempat Penelitian}

Lokasi penelitian ini di Universitas Indraprasta PGRI, Jalan Nangka No. 58 C (T.B. Simatupang) Jagakarsa - Jakarta Selatan. Peneliti menegaskan waktu penelitian dalam bentuk jadwal penelitian agar penelitian 
ini lebih sistematis dan terukur pelaksanaannya. Proses penelitian berlangsung dari bulan September 2019 sampai Februari 2020.

\section{Target / Subjek Penelitian / Populasi dan Sampel}

Populasi dalam penelitian ini adalah para mahasiswa semester I prodi Arsitektur di Universitas Indraprasta PGRI yang memiliki nilai ulangan tengah semester dibawah KKM dimana terdiri dari 8 kelas dengan rata-rata jumlah mahasiswanya 30. Sedangkan sampel dalam penelitian ini adalah mahasiswa yang memiliki nilai ulangan tengah semester dibawah KKM. Teknik sampling menggunakan simple random sampling karena pengambilan sampel anggota populasi dilakukan secara acak tanpa memperhatikan strata yang ada dalam populasi. Dari 8 kelas yang menjadi sampel penelitian ada 60 mahasiswa, dimana 30 mahaiswa akan dijadikan kelas eksperimen dan 30 mahasiswa akan dijadikan kelas kontrol.

\section{Data, Instrumen, dan Teknik Pengumpulan Data}

Data yang digunakan dalam penelitian ini untuk uji hipotesis yaitu nilai hasil ulangan yang diadakan setelah pengajaran remedial. Instrumen penelitian berupa soal esay sebanyak 5 soal dan lama waktunya $2 \times 45$ menit. Instrumen yang digunakan dalam penelitian ini sudah diujicobakan di kelas uji coba penelitian dan untuk perhitungan uji validitas dan uji reliabilitas butir soalnya menggunakan bantuan SPSS 16.0. Setelah diadakan ulangan, peneliti mengadakan wawancara pada mahasiswa untuk mengetahui kesulitan yang dihadapi mahasiswa selama proses belajar.

Teknik pengumpulan data dalam penelitian ini yaitu: (1) Metode dokumentasi untuk mengetahui mahasiswa yang menjadi populasi dan sampel. Serta untuk mengetahui kesulitan yang dialami oleh mahasiswa; (2) Metode tes untuk mengetahui hasil belajar mata kuliah matematika teknik tiap mahasiswa; dan (3) Metode wawancara untuk menanyakan respon terhadap program pengajaran remedial.

\section{Teknik Analisis Data}

Teknik analisis data merupakan prosedur penelitian yang digunakan untuk proses data agar data mempunyai makna untuk menjawab masalah dalam penelitian ini dan menguji hipotesis. Data dianalisis secara bertahap dengan mengolah data hasil tes yang diperoleh. Sebelum data digunakan untuk uji hipotesis maka peneliti melakukan uji prasyarat penelitian dimaksudkan untuk mengukur atau menguji kesamaan awal kedua kelompok perlakuan. Adapun uji prasyarat ini meliput uji normalitas menggunakan uji Lilliefors, uji ini untuk mengetahui penyebaran sampel penelitian bersifat normal atau tidak dan uji homogenitas menggunakan uji $\mathrm{F}$ untuk mengetahui sampel penelitian berasal dari populasi yang homogen atau tidak.

Jika uji prasyarat telah dilakukan maka dilanjut uji hipotesis.. Uji hipotesis menggunakan uji t untuk dapat mengetahui adanya peningkatan hasil belajar bagi mahasiswa semester I Program Studi Arsitektur Universitas Indraprasata PGRI setelah diadakan pengajaran remidial. Dan wawancara untuk mengetahu kesuliitan yang dihadapi mahasiswa dalam memahami materi yang diajarkan.

\section{HASIL DAN PEMBAHASAN Hasil Penelitian}

Sebelum data dianalisa dan melakukan uji hipotesis, data harus diuji normalitas dan uji homogenitas terlebih dahulu. Uji normalitas data dilakukan dengan uji Lilliefors dan taraf signifikansi $\alpha=0,05$ dengan bantuan Microsoft Excel. Rangkuman hasil uji normalitas disajikan pada tabel berikut ini. 
Tabel 1. Hasil Perhitungan Uji Normalitas Kelas Eksperimen

\begin{tabular}{|c|c|c|c|c|c|c|c|c|}
\hline SKOR & $\mathbf{f}$ & $\mathbf{f k u m}$ & $\mathbf{Z i}$ & $\begin{array}{c}\text { Nilai } \\
\text { Tabel }\end{array}$ & $\mathbf{F}(\mathbf{Z i})$ & $\mathbf{S}(\mathbf{Z i})$ & $\mathbf{F}(\mathbf{Z i})-\mathbf{S}(\mathbf{Z i})$ & $\mathbf{I} \mathbf{F}(\mathbf{Z i})-\mathbf{S}(\mathbf{Z i}) \mathbf{I}$ \\
\hline 14 & 1 & 1 & $-1,74$ & 0,4591 & 0,041 & 0,033 & 0,008 & 0,008 \\
\hline 15 & 1 & 2 & $-1,39$ & 0,4177 & 0,082 & 0,067 & 0,016 & 0,016 \\
\hline 16 & 5 & 7 & $-1,04$ & 0,3508 & 0,149 & 0,233 & $-0,084$ & 0,084 \\
\hline 17 & 4 & 11 & $-0,70$ & 0,2734 & 0,227 & 0,367 & $-0,140$ & $\mathbf{0 , 1 4 0}$ \\
\hline 18 & 1 & 12 & $-0,35$ & 0,1368 & 0,363 & 0,400 & $-0,037$ & 0,037 \\
\hline 20 & 4 & 16 & 0,35 & 0,1368 & 0,637 & 0,533 & 0,103 & 0,103 \\
\hline 21 & 10 & 26 & 0,70 & 0,2734 & 0,773 & 0,867 & $-0,093$ & 0,093 \\
\hline 23 & 2 & 28 & 1,39 & 0,3508 & 0,851 & 0,933 & $-0,083$ & 0,083 \\
\hline 24 & 1 & 29 & 1,74 & 0,4591 & 0,959 & 0,967 & $-0,008$ & 0,008 \\
\hline 25 & 1 & 30 & 2,09 & 0,4817 & 0,982 & 1,000 & $-0,018$ & 0,018 \\
\hline & 30 & & & & & & & \\
\hline
\end{tabular}

Berdasarkan Tabel 5.1.1 dapat disimpulkan bahwa $\mathrm{H}_{0}$ diterima karena $\mathrm{L}_{\text {hitung }}=0,140<\mathrm{L}_{\text {tabel }}$ $=0,161$. Artinya peserta didik yang diajarkan menggunakan metode tutor sebaya dalam pengajaran remedial berdistribusi normal.

Tabel 2. Hasil Perhitungan Uji Normalitas Kelas Kontrol

\begin{tabular}{|c|c|c|c|c|c|c|c|c|}
\hline SKOR & $\mathbf{f}$ & $\mathbf{f k u m}$ & $\mathbf{Z i}$ & $\begin{array}{c}\text { Nilai } \\
\text { Tabel }\end{array}$ & $\mathbf{F}(\mathbf{Z i})$ & $\mathbf{S}(\mathbf{Z i})$ & $\mathbf{F}(\mathbf{Z i})-\mathbf{S}(\mathbf{Z i})$ & $\mathbf{I} \mathbf{F}(\mathbf{Z i})-\mathbf{S}(\mathbf{Z i}) \mathbf{I}$ \\
\hline 14 & 1 & 1 & $-2,090$ & 0,4817 & 0,018 & 0,033 & $-0,015$ & 0,015 \\
\hline 16 & 2 & 3 & $-1,254$ & 0,3944 & 0,106 & 0,100 & 0,006 & 0,006 \\
\hline 17 & 5 & 8 & $-0,836$ & 0,2995 & 0,201 & 0,267 & $-0,066$ & 0,066 \\
\hline 18 & 5 & 13 & $-0,418$ & 0,1628 & 0,337 & 0,433 & $-0,096$ & 0,096 \\
\hline 20 & 11 & 24 & 0,418 & 0,1628 & 0,663 & 0,800 & $-0,137$ & $\mathbf{0 , 1 3 7}$ \\
\hline 21 & 2 & 26 & 0,836 & 0,2995 & 0,800 & 0,867 & $-0,067$ & 0,067 \\
\hline 22 & 2 & 28 & 1,254 & 0,3944 & 0,894 & 0,933 & $-0,039$ & 0,039 \\
\hline 24 & 1 & 29 & 2,090 & 0,4817 & 0,982 & 0,967 & 0,015 & 0,015 \\
\hline 25 & 1 & 30 & 2,508 & 0,494 & 0,994 & 1,000 & $-0,006$ & 0,006 \\
\hline & 30 & & & & & & & \\
\hline
\end{tabular}

Berdasarkan Tabel 5.1.2 dapat disimpulkan bahwa $\mathrm{H}_{0}$ diterima karena $\mathrm{L}_{\text {hitung }}=0,137<\mathrm{L}_{\text {tabel }}$ $=0,161$. Artinya peserta didik yang diajarkan menggunakan metode pemberian tugas dalam pengajaran remedial berdistribusi normal.

Sedangkan untuk uji homogenitas data dilakukan dengan uji $F$ dan taraf signifikansi $\alpha=$ 0,05 dengan bantuan Microsoft Excel. Rangkuman hasil uji homogenitas disajikan pada tabel berikut ini. 
Tabel 3. Hasil Perhitungan Uji Homogenitas

\begin{tabular}{|c|l|l|}
\hline NO. & Y1 & Y2 \\
\hline 1 & 20 & 18 \\
\hline 2 & 16 & 17 \\
\hline 3 & 25 & 25 \\
\hline 4 & 16 & 16 \\
\hline 5 & 20 & 20 \\
\hline 6 & 14 & 14 \\
\hline 7 & 21 & 21 \\
\hline 8 & 17 & 20 \\
\hline 9 & 21 & 20 \\
\hline 10 & 20 & 20 \\
\hline 11 & 21 & 18 \\
\hline 12 & 18 & 17 \\
\hline 13 & 17 & 20 \\
\hline 14 & 24 & 24 \\
\hline 15 & 23 & 22 \\
\hline 16 & 21 & 18 \\
\hline 17 & 17 & 20 \\
\hline 18 & 16 & 16 \\
\hline 19 & 16 & 17 \\
\hline 20 & 21 & 20 \\
\hline 21 & 21 & 18 \\
\hline 22 & 23 & 17 \\
\hline 23 & 16 & 22 \\
\hline 24 & 17 & 20 \\
\hline 25 & 20 & 21 \\
\hline 26 & 21 & 20 \\
\hline 27 & 21 & 20 \\
\hline 28 & 15 & 18 \\
\hline 29 & 21 & 20 \\
\hline 30 & 21 & 17 \\
\hline total & $\mathbf{5 8 0}$ & $\mathbf{5 7 6}$ \\
\hline $\mathbf{x} \mathbf{b a r}$ & $\mathbf{1 9 , 3 3}$ & $\mathbf{1 9 , 2 0}$ \\
\hline $\mathbf{S}$ & $\mathbf{2 , 8 8}$ & $\mathbf{2 , 3 9}$ \\
\hline$s^{2}$ & $\mathbf{8 , 2 8}$ & $\mathbf{5 , 7 2}$ \\
\hline $\mathbf{F}$ & & $\mathbf{1 , 4 5}$ \\
\hline & & \\
\hline
\end{tabular}

Berdasarkan tabel 5.1.3 dapat disimpulkan bahwa $\mathrm{H}_{0}$ diterima karena $\mathrm{F}_{\text {hitung }}$ $=1,45<\mathrm{F}_{\text {tabel }}=1,94$. Artinya peserta didik yang diajarkan menggunakan metode tutor sebaya dengan peserta didik yang diajarkan menggunakan metode pemberian tugas dalam pengajaran remedial berasal dari populasi yang homogen.

Setelah diuji normalitas dan uji homogenitas tahap selanjutnya yaitu melakukan uji hipotesis dimana untuk uji hipotesis data dilakukan dengan uji $t$ dan taraf signifikansi $\alpha=0,05$ dengan bantuan Microsoft Excel. Rangkuman hasil uji hipotesisnya sebagai berikut ini.

Jika:

$\bar{X}_{1}=19,33$

$\bar{X}_{2}=19,20$

$S_{1}^{2}=8,28$

$S_{2}^{2}=5,72$

Maka:

$t=\frac{\bar{X}_{1}-\bar{X}_{2}}{\sqrt{\frac{S_{1}^{2}}{n_{1}}+\frac{S_{2}^{2}}{n_{2}}}}$

$t=\frac{19,33-19,20}{\sqrt{\frac{8,28}{30}+\frac{5,72}{30}}}$

$t=0,195$

Berdasarkan perhitungan diatas dapat disimpulkan bahwa $\mathrm{H}_{0}$ diterima karena $\mathrm{t}_{\text {hitung }}=$ $0,195<\mathrm{t}_{\text {tabel }}=1,671$. Artinya peserta didik yang diajarkan menggunakan metode tutor sebaya dengan mahasiswa yang diajarkan menggunakan metode pemberian tugas dalam pengajaran remedial memiliki pengaruh yang signifikan.

\section{Pembahasan}

Penelitian ini dilaksanakan setelah Ujian Tengah Semester Gasal Tahun Ajaran 2019/2020 tepatnya pada tanggal 12,13 , dan 14 November 2019. Sampel penelitian sebanyak 60 mahasiswa dimana 30 mahasiswa dijadikan kelas eksperimen dengan pengajaran remedial menggunakan metode tutor sebaya dan 30 mahasiswa dijadikan kelas kontrol dengan pengajaran remedial menggunakan metode tanya jawab. Responden dalam penelitian ini juga telah diuji normalitas dan homogenitas, dimana dari uji tersebut menunjukan responden berdistribusi normal (tabel 5.1.1 dan tabel 5.1.2) dan homogenitas (5.1.3)

Langkah pertama dalam penelitian ini yaitu tim peneliti mendiagnosis kesalahan yang dilakukan oleh para mahasiswa terutama bagi mereka yang tidak tuntas pada mata kuliah matematika teknik. Diagnosis dilakukan dari hasil tes yang kemudian 
dianalisis jenis kesalahan yang telah dilakukan, jenis kesalahan tersebut yaitu (1) Kesalahan Konsep, (2) Kesalahan Interpretasi Bahasa, (3) Kesalahan Menggunakan Data, (4) Kesalahan Teknis, dan (5) Kesalahan Penarikan Kesimpulan.

Langkah kedua, pengajar mengadakan pengajaran remedial dengan metode tutor sebaya pada kelas eksperimen dan metode pemberian tugas pada kelas kontrol. Pada kelas eksperimen, mahasiswa dibentuk kelompok yang terdiri dari 3-4 anggota dan setiap kelompok akan dibimbing belajarnya oleh satu mahasiswa yang dianggap paling pintar (sudah tuntas untuk nilai mata kuliah matematika teknik). Pada kelas kontrol, mahasiswa juga dibentuk kelompok yang terdiri 3-4 anggota dan pengajar memberikan tugas tambahan sesuai dengan kesulitan yang dihadapi. Tugas yang diberikan harus jelas petunjuk pengerjaanya dan harus cermat dalam membuat patokan penilaian.

Langkah ketiga, diadakannya tes untuk mengetahui peningkatan hasil belajar setelah diadakannya pengajaran remedial serta untuk mengetahui perbedaan mahasiswa yang diajarkan dengan metode tutor sebaya dengan mahasiswa yang diajarkan dengan metode pemberian tugas. Soal berbentuk essay yang terdiri dari 5 nomor dan hasil tes diproses untuk pengujian hipotesis.

Hasil pengolahan dan analisis data penelitian diperoleh temuan bahwa adanya perbedaan yang signifikan peningkatan hasil belajar antara mahasiswa yang diajarkan menggunakan metode tutor sebaya dengan peserta didik yang diajarkan menggunakan metode pemberian tugas dalam pengajaran remedial. Pernyataan ini berdasarkan hasil perhitungan uji hipotesis dengan menggunakan uji $\mathrm{t}$ dimana hasilnya menunjukan $t_{\text {hitung }}=0,195<t_{\text {tabel }}=1,671$. Serta jika dilihat dari nilai rata-rata perkelas dapat disimpulkan bahwa hasil belajar antara mahasiswa yang diajarkan menggunakan metode tutor sebaya lebih tinggi dari pada peserta didik yang diajarkan menggunakan metode pemberian tugas dalam pengajaran remedial
Hal ini juga sesuai dengan penelitian Elly Nurlia Rustiani (2016) yang menyimpulkan bahwa terdapat perbedaan hasil belajar matematika antara siswa yang diberi program remedial melalui metode tutor sebaya dengan (lebih tinggi dari) metode pemberian tugas. Penelitian Rendy Nugraha Frasandy (2017) juga menyimpulkan bahwa remedial teaching melalui metode tutor sebaya dalam pengajaran Fikih leih efektif dibandingkan dengan metode konvensional untuk meningkatkan hasil belajar.

Serta penelitian Aulia dkk (2017) yang menyimpulkan bahwa terdapat perbedaan yang signifikan anara pemberian remedial teaching dengan metode tutor sebaya terhadap hasil belajar matematika siswa di kelas VIII SMP pada tingkat kepercayaan 95\%. Hasil belajar matematika siswa yang diberikan remedial teaching menggunakan metode tutor sebaya lebih tinggi dibandingkan dengan siswa yang diberiakan remedial teaching menggunakan metode pemberian tugas.

Langkah terakhir pada penelitian ini yaitu pengajar mengadakan wawancara terhadap mahasiswa yang mengikuti pengajaran remedial. Wawancara ini bertujuan untuk mengetahui respon mahasiswa tentang pengajaran remedial dan mengetahui kesulitan yang dialaminya. Dari hasil wawancara dapat disimpulkan para mahasiswa merasa terbantu dengan adanya pengajaran remedial, mereka dapat mengetahui materi yang sebelumnya tidak dipahami bahkan menambah pengetahuan karena mendapatkan materi yang tidak diajarkan pada pembelajaran reguler. Serta mahasiswa dapat memperbaiki cara-cara belajar yang baik.

Sedangkan kesulitan yang dialami para mahasiswa dalam mengerjakan soal ujian tengah semester antara.lain:

1) Membaca soal untuk dapat menentukan makna kata dari kata kunci di dalam soal.

2) Memisahkan dan menentukan apa yang diketahui dan apa yang ditanyakan.

3) Menentukan metode yang akan digunakan untuk menyelesaikan soal. 
4) Menyelesaikan soal menurut aturan-aturan matematika, sehingga mendapatkan jawaban dari masalah yang dipecahkan.

5) Menulis jawaban dengan tepat.

Kesulitan yang dihadapi mahasiswa dalam mengerjakan soal matematika akan dapat teratasi jika mereka mengetahui lagkahlangkah yang benar dalam mencari penyelesaian. Hal ini sesuai pendapat Haji (dalam R Amalia, 2017: 28) bahwa lima langkah penyelesaian soal cerita yang didasarkan pada lima kemampuan siswa, yaitu (a) kemampuan membaca soal; (b) kemampuan menentukan apa yang diketahui dan apa yang ditanyakan dalam soal, (c) kemampuan membuat model matematika, (d) kemampuan melakukan perhitungan dan (e) kemampuan menentukan jawaban akhir dengan tepat.

\section{PENUTUP}

Kesimpulan yang didapat dari hasil penelitian ini yaitu:

a. Adanya perbedaan peningkatan hasil belajar bagi mahasiswa semester I Program Studi Arsitektur Universitas Indraprasata PGRI yang diajarkan menggunakan metode tutor sebaya dengan metode pemberian tugas dalam pengajaran remedial. Perbedaan peningkatan hasil belajar dapat dilihat dari nilai rata-rata kelas yang didapat, pada mahasiswa yang diajar menggunakan metode tutor sebaya nilai ata-rata kelasnya yaitu 19,33 sedangakan mahasiswa yang diajarkan dengan metode pemberian tugas nilai ratarata kelasnnya yaitu 19,20

b. Respon mahasiswa terhadap penerapan program pembelajaran remedial yang telah dilaksanakan rata-rata positif, merekan menjadi paham tentang materi yang diajarkan dan menemukan solusi dalam mengetasi kesulitan dalam belajarnya.

\section{DAFTAR PUSTAKA}

Ahmadi, A \& Supriyono, W. 2013. Psikologi Belajar. Jakarta: PT. Rineka Cipta.

Amalia, R. 2017. PENGEMBANGAN MODUL SOAL CERITA DALAM MODEL VAK (VISUALIZATION, AUDITORY, KINESTETIC) KELAS VIII SMP MUHAMMADIYAH 06 DAU (Doctoral dissertation, University of Muhammadiyah Malang).

Frasandy, R. N. 2018. Penerapan Program Remedial Teaching Melalui Metode Tutor Sebaya Terhadap Hasil Belajar Siswa Madrasah Ibtidaiyah Negeri Kabupaten Sleman Yogyakarta. AtTa'lim: Media Informasi Pendidikan Islam, 16(1), 89-105.

Kusumasari, Yulitta Radita. 2007. Meningkatkan Hasil Belajar Matematika Melalui Metode Tutor Sebaya dalam Pengajaran Remedial pada Siswa Kelas VIII Semester II SMP Negeri 25 Semarang Tahun Pelajaran 2006/2007. Semarang : Universitas Negeri Semarang.

Mulyadi. 2010. Diagnosis Kesulitan Belajar dan Bimbingan terhadap Kesulitan Belajar Khusus. Yogyakarta: Nuha Litera.

Mutakin, T.Z. dan Teti Sumiati. 2011. Pengaruh penggunaan media belajar dan minat belajar terhadap hasil belajar matematika. Jurnal Formatif. 1(1): 7080

PUTRI, Aulia. STUDI PERBANDINGAN PEMBERIAN TEACHING REMEDIAL METODE TUTOR SEBAYA DAN METODE PEMBERIAN TUGAS TERHADAP HASIL BELAJAR MATEMATIKA SISWA KELAS VIII SMP NEGERI 24 MUARO JAMBI. Jurnal Pendidikan Matematika. 
Rustiani, E. N. 2016. Pengaruh Program Remedial dan Gaya Kognitif terhadap Hasil Belajar Matematika. Jurnal Penelitian dan Penilaian Pendidikan, 1(1), 32-46.

Sukardi, M. 2011. Evaluasi Pendidikan: Prinsip dan Operasinya. Jakarta: PT. Bumi Aksara.

Suriasumantri, Juju S. (2009). Flsafat Ilmu (Sebuah Pengantar Populer). Jakarta: Pustaka Sinar Harapan. 